\title{
"Wet" transepithelial phototherapeutic keratectomy in the management of persistent epithelial defects in the graft
}

This article was published in the following Dove Press journal:

Clinical Ophthalmology

\author{
Sergei V Churashov' \\ Elena $\vee$ Kudryashova ${ }^{\prime}$ \\ Alexei N Kulikov' \\ Ernest $\mathrm{V}$ Boiko ${ }^{1-3}$ \\ Valerii F Chernysh' \\ Dmitrii S Maltsev' \\ 'Department of Ophthalmology, \\ Military Medical Academy, \\ St Petersburg, Russia; ${ }^{2}$ St Petersburg \\ Branch, The S Fyodorov Eye \\ Microsurgery Federal State Institution, \\ St Petersburg, Russia; ${ }^{3}$ Department \\ of Ophthalmology, Mechnikov \\ North-Western State Medical \\ University, St Petersburg, Russia
}

Purpose: This study aimed to evaluate the efficacy of "wet" transepithelial phototherapeutic keratectomy (TE-PTK) for treating persistent epithelial defects (PEDs) in the corneal graft following penetrating keratoplasty (PKP).

Methods: This study describes a noncomparative, prospective interventional case series. Patients with post-PKP graft epithelial defects lasting $>3$ months despite previous treatments with extensive wear soft contact lenses, amniotic membrane transplantation, and tarsorrhaphy were treated with wet TE-PTK. A wet TE-PTK procedure including a "wet ablation" step was performed using the EC-5000 excimer laser. Follow-up visits were at post-PTK days 3, 5, 10, and 30 , and at each month thereafter.

Results: Eight patients ( 8 eyes; 5 men and 3 women; mean age, $51.3 \pm 14.3$ years; mean follow-up period, 9.1 \pm 3.0 months) were included in this study. The mean best-corrected visual acuity was $1.76 \pm 0.28 \log$ minimum angle of resolution (logMAR) at baseline and improved to $1.1 \pm 0.22 \log$ MAR at 10 days postoperatively ( $p=0.0156$; the improvement was significant). This effect remained stable throughout the remainder of the follow-up period. The mean time from wet TE-PTK to complete reepithelization was $4.3 \pm 1.3$ days.

Conclusion: Wet TE-PTK appears to be effective for patients with post-PKP PEDs in the corneal graft who have failed conservative measures or previous surgical interventions.

Keywords: phototherapeutic keratectomy, persistent epithelial defects, penetrating keratoplasty, transepithelial phototherapeutic keratectomy, recurrent corneal erosion

\section{Introduction}

Recurrent corneal erosion (RCE) syndrome is a condition that features repeated spontaneous episodes of loss of epithelial adhesion in the cornea, resulting from basal membrane abnormalities, and may be associated with various corneal diseases. ${ }^{1}$

A persistent epithelial defect (PED) is a similar condition characterized by loss of integrity of the corneal epithelial layer, the condition being present for $>2$ weeks despite appropriate medical therapy. ${ }^{2}$ The PEDs developing in the graft following penetrating keratoplasty (PKP) cause delay in visual rehabilitation and significant discomfort to the patient, as well as predisposing the graft to infectious complications. ${ }^{3}$

It is estimated that as many as $25 \%$ of grafts may develop signs of anterior surface pathology, ${ }^{4}$ including epithelial defects of various severities and durations. Although the PEDs are less common than some other disorders of the anterior graft surface, their management remains an important issue due to resistance to the majority of treatments.
Correspondence: Dmitrii S Maltsev Department of Ophthalmology, Military Medical Academy, 5 Klinicheskaya Street, St Petersburg 194044, Russia

$\mathrm{Tel} / \mathrm{fax}+78125429264$

Email glaz.med@yandex.ru 
Phototherapeutic keratectomy (PTK) is a valuable technique in treating recurrent erosions of various etiologies; 5,6 it is rather efficacious and allows the physician to achieve the arrest of erosion even after other surgical treatments have failed. ${ }^{7,8}$ However, to the best of our knowledge, there have been no reports on the use of PTK for the management of PEDs in the graft. A mix of reepithelialized and eroded corneal sites is a difficulty that may arise in performing a PTK in PED. Under these circumstances, nonselective ablation would result in a substantial stromal defect within the zone of erosion, as the stroma outside the zone is masked by the epithelium. Because the issue can be solved with the use of a masking agent, the purpose of the study was to assess the efficacy of "wet" transepithelial PTK (TE-PTK) for the management of PEDs in the graft following PKP.

\section{Methods}

The study adhered to the tenets of the Declaration of Helsinki and was approved by the Institutional Review Board/Ethics Committee of the Military Medical Academy; all participants provided written informed consent. This interventional case series comprised patients with post-PKP graft epithelial defects lasting $>3$ months who were treated with wet TEPTK after failure of previous treatments with extended wear soft contact lenses, amniotic membrane transplantation (AMT), and tarsorrhaphy, and followed prospectively for at least 6 months after PTK.
Exclusion criteria were signs of stromal or endothelial graft rejection, erosion spreading outward from the corneal suture, ophthalmic hypertension/glaucoma in the post-PKP eye, silicone tamponade of the vitreous cavity, severe tear deficiency dry eye, and severe limbal stem cell deficiency (LSCD), with the diagnosis of severe LSCD (with $>180^{\circ}$ of limbal involvement), if any, made clinically by the loss of limbal palisades of Vogt and confirmed by demonstration of goblet cells on the corneal surface using impression cytology. The etiology of LSCD was chemical injury in all 3 patients with partial LSCD included in the study (Table 1).

All the patients underwent visual acuity assessment and anterior segment biomicroscopy with fluorescein staining 1 day before PTK and at post-PTK days 3, 5, 10 ( \pm 2 days), and 30 ( \pm 5 days), as well as at each month thereafter. Patients were asked about any ocular surface discomfort and the need for ocular lubricants. Schirmer tear test strips (Optitech Eyecare, Allahabad, Uttar Pradesh, India) were used to diagnose dry eye disease.

\section{TE-PTK technique}

PTK was performed with the EC-5000 Excimer Laser (Nidek, Inc, Tokyo, Japan) after triple instillation of topical $0.5 \%$ proparacaine hydrochloride (Alcaine; Alcon Couvreur NV, Puurs, Belgium). The laser spot diameter was set to less than the diameter of the graft suture if the corneal suture was still

Table I Demographic data and medical history

\begin{tabular}{|c|c|c|c|c|c|c|c|c|}
\hline $\begin{array}{l}\text { Patient } \\
\text { number }\end{array}$ & $\begin{array}{l}\text { Age, } \\
\text { years }\end{array}$ & Gender & $\begin{array}{l}\text { Reasons for } \\
\text { keratoplasty }\end{array}$ & $\begin{array}{l}\text { Supposed } \\
\text { cause for PED } \\
\text { in the graft }\end{array}$ & $\begin{array}{l}\text { Schirmer } \\
\text { test, mm }\end{array}$ & $\begin{array}{l}\text { Maximum } \\
\text { dimension of PED } \\
\text { in the graft, } \mathrm{mm}\end{array}$ & $\begin{array}{l}\text { Duration of } \\
\text { PED in the } \\
\text { graft, months }\end{array}$ & $\begin{array}{l}\text { Manipulations } \\
\text { following } \\
\text { keratoplasty }\end{array}$ \\
\hline 1 & 44 & $M$ & Ocular trauma & $\begin{array}{l}\text { Silicone oil } \\
\text { keratopathy }\end{array}$ & 24 & 3.2 & 3 & $\begin{array}{l}\text { BSCL; } 2 \text { AMT } \\
\text { procedures }\end{array}$ \\
\hline 2 & 68 & $\mathrm{~F}$ & Post-CPE EED & Dry eye disease & 13 & 4.5 & 4 & $\begin{array}{l}\mathrm{BSCL} \text {; I AMT } \\
\text { procedure }\end{array}$ \\
\hline 3 & 56 & M & Chemical injury & $\begin{array}{l}\text { Partial LSCD; } \\
\text { dry eye disease }\end{array}$ & 6 & 5.0 & 4 & $\begin{array}{l}\text { BSCL; } 2 \text { AMT } \\
\text { procedures }\end{array}$ \\
\hline 4 & 52 & $M$ & Chemical injury & $\begin{array}{l}\text { Partial LSCD; } \\
\text { dry eye disease }\end{array}$ & 7 & 4.7 & 5 & $\begin{array}{l}\text { BSCL; } 3 \text { AMT } \\
\text { procedures; } \\
\text { tarsorrhaphy }\end{array}$ \\
\hline 5 & 71 & $\mathrm{~F}$ & Post-CPE EED & Not established & 12 & 3.5 & 4 & $\begin{array}{l}\text { BSCL; } 2 \text { AMT } \\
\text { procedures; } \\
\text { tarsorrhaphy }\end{array}$ \\
\hline 6 & 53 & $M$ & Keratitis & Not established & 22 & 2.1 & 3 & $\begin{array}{l}\text { BSCL; } 2 \text { AMT } \\
\text { procedures }\end{array}$ \\
\hline 7 & 36 & $\mathrm{~F}$ & Chemical injury & Not established & 17 & 4.4 & 5 & $\begin{array}{l}\text { BSCL; } 2 \text { AMT } \\
\text { procedures }\end{array}$ \\
\hline 8 & 30 & M & Chemical injury & Partial LSCD & 18 & 5.5 & 6 & $\begin{array}{l}\text { BSCL; I AMT } \\
\text { procedure }\end{array}$ \\
\hline
\end{tabular}

Abbreviations: AMT, amniotic membrane transplantation; BSCL, bandage soft contact lens; CPE, cataract phacoemulsification; EED, endothelial and epithelial dystrophy; F, female; LSCD, limbal stem cell deficiency; M, male; PED, persistent epithelial defect. 

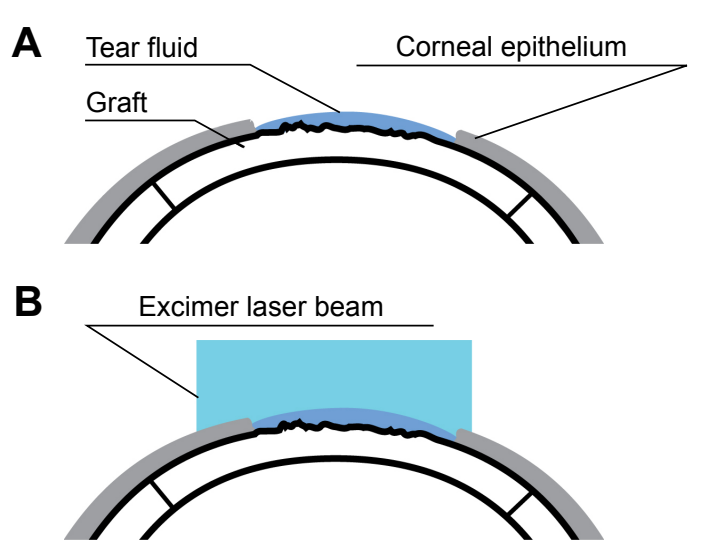

C

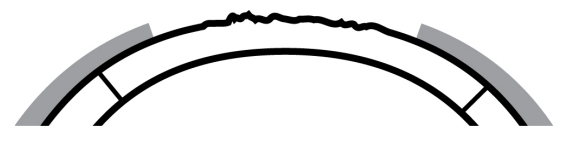

D

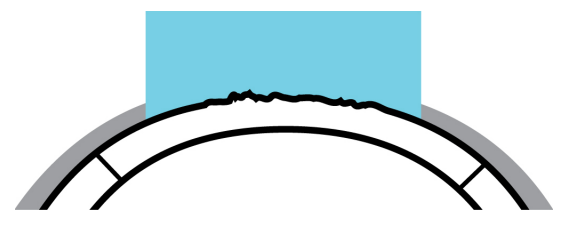

$\mathbf{E}$

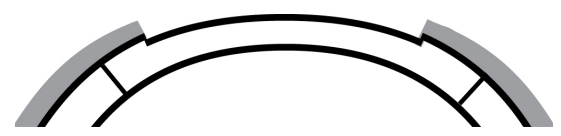

Figure I Steps of wet transepithelial phototherapeutic keratectomy (TE-PTK) in the management of persistent epithelial defects in the graft.

Notes: (A) The surface of the graft was dried, except for the area of erosion. (B) A $50 \mu \mathrm{m}$ epithelial ablation was performed as the first ablation stage. (C) The surface of erosion was completely dried. (D) The second ablation stage was performed up to a depth of $10 \mu \mathrm{m}$. (E) The ablation was stopped when a uniform and smooth anterior stromal surface was visualized in laser spot projection.

present at the time of PTK. The eye was fixed with a forceps if the patient's fixation was poor.

Prior to ablation, tear fluid was removed from the entire surface of the graft, except the area of erosion. The first stage (ie, a "wet ablation" step) of ablation was performed using tear fluid as a masking agent in the zone of PED, and it involved a $50 \mu \mathrm{m}$ epithelial ablation as the first substage. Laser ablation depth was determined using the laser's software and monitored visually. Additional epithelial ablations (ie, the second substage) within a "wet ablation" step were carried out until the boundary between the epithelialized portion of the graft and the zone of erosion disappeared. After completion of epithelial ablation, the surface of erosion was completely dried, and the second ablation stage was performed up to a depth of $10 \mu \mathrm{m}$. The ablation was stopped when a uniform and smooth anterior stromal surface was visualized in the laser spot projection (Figure 1).

On conclusion of the PTK procedure, tobramycindexamethasone drops (Tobradex; Alcon) were instilled, and a bandage soft contact lens (BSCL) was placed. Postoperative therapy included instillation of Tobradex (6 times daily) and liquid ocular lubricant (Artelac Splash; Bausch and Lomb, Inc, North Bridgewater, NJ, USA; 6 times daily) as well as viscous ocular lubricant (Corneregel; Bausch and Lomb, Inc; 3 times daily). Any other topical drop therapies were completely suspended from the time of commencement of PTK and resumed after BSCL removal.

Each BSCL was worn for 24 hours and replaced daily with a fresh one after fluorescein staining was assessed by biomicroscopy. If complete or nearly complete reepithelialization of the graft was present, lens wear and Tobradex were discontinued, while the therapy that was used prior to PTK was resumed at the same schedule.

\section{Statistical analysis}

Statistical analysis was performed using Statistica 10 software (StatSoft, Inc, Tulsa, OK, USA). Data were presented as mean values $\pm \mathrm{SD}$. Wilcoxon signed-rank test was used to assess the significance of differences between preoperative and postoperative visual acuities. Visual acuities were measured in decimal units and converted to log minimum angle of resolution (logMAR) equivalent for statistical analysis.

\section{Results}

Eight patients ( 8 eyes; 3 women and 5 men; mean age, $51.3 \pm 14.3$ years) were included in the study. The mean period between keratoplasty and the formation of PED was $13.7 \pm 5.5$ days.

\section{Previous treatments and pre-PTK complaints}

Attempts (intensive use of ocular lubricants, BSCL, and 1-3 AMTs) were made to achieve reepithelialization in each study eye prior to PTK. In 2 cases, AMT was combined with temporary tarsorrhaphy (Table 1). Preoperatively, each patient complained of ocular discomfort, burning, and/or foreign body sensation in the eye with PED. 
Table 2 Changes in BCVA after phototherapeutic keratectomy, laser settings, and follow-up details

\begin{tabular}{llllll}
\hline $\begin{array}{l}\text { Patient } \\
\text { number }\end{array}$ & $\begin{array}{l}\text { Preoperative } \\
\text { logMAR } \\
\text { BCVA }\end{array}$ & $\begin{array}{l}\text { Postoperative } \\
\text { logMAR } \\
\text { BCVA }\end{array}$ & $\begin{array}{l}\text { Ablation profile (ablation } \\
\text { diameter [mm] } \times \text { total } \\
\text { ablation depth }[\mu \mathrm{m}] \text { ) }\end{array}$ & $\begin{array}{l}\text { Time for complete } \\
\text { reepithelialization } \\
\text { of the defect, days }\end{array}$ & $\begin{array}{l}\text { Duration of } \\
\text { follow-up, } \\
\text { months }\end{array}$ \\
\hline 1 & 1.5 & 1 & $4.5 \times 55$ & 3 & 10 \\
2 & 2 & 0.7 & $5 \times 58$ & 4 & 9.5 \\
3 & 1.5 & 1 & $6 \times 53$ & 4 & 10.5 \\
4 & 2 & 1.2 & $5.5 \times 57$ & 3 & 12 \\
5 & 2 & 1.3 & $5 \times 60$ & 3 & 7 \\
6 & 1.7 & 1 & $5 \times 59$ & 6 & 8 \\
7 & 2 & 1.3 & $6 \times 53$ & 6 & 6 \\
8 & 1.3 & 1.3 & $10 \times 59$ & 6 & 6 \\
\hline
\end{tabular}

Abbreviations: BCVA, best-corrected visual acuity; CPE, cataract phacoemulsification; logMAR, log minimum angle of resolution.

\section{Visual acuity and time for complete reepithelialization of the defect}

The mean $\log$ MAR best-corrected visual acuity (BCVA) changed from $1.76 \pm 0.28$ prior to PTK to $1.1 \pm 0.22$ at Day 10 after PTK ( $p=0.027)$ and did not change subsequently. The mean follow-up period was $9.1 \pm 3.0$ months (Table 2 ). The mean time for complete reepithelialization of the defect was $4.3 \pm 1.3$ days, and in no case did the patient wear BSCL at Day 7 or later after PTK (Figure 2).

\section{Surgical and postoperative ocular events}

One case developed an epithelial bulla 6 weeks after PTK; however, this did not progress to erosion (the bulla resolved within 3 weeks). One case (patient number 8 ) associated with partial LSCD demonstrated an epithelial defect $(2 \times 2 \mathrm{~mm})$ outside the graft 4 weeks after PTK; with increased application of lubricants, the defect resolved within 7 days. In that patient, the PTK was performed after removal of the corneal suture and using a large ablation zone, and this was the only patient in whom the last stage of the procedure was complicated by bleeding from peripheral corneal neovascularization. Although the ophthalmologist had to interrupt the procedure several times to remove blood while performing total ablation of the graft zone in the case, this bleeding did not prevent him from completing the PTK procedure.

After reepithelization was complete, 1) no patient complained of burning, foreign body sensation, or other ocular discomfort; and 2) anterior segment biomicroscopy with fluorescein staining revealed no epithelial defects at any of the subsequent follow-up visits, with the exception of the mentioned patient with an epithelial defect outside the graft at 4 weeks after PTK. There were no early complications after PTK. A PTK was performed in the presence of a continuous corneal suture in 7 patients. In 4 of these, the suture was removed during the follow-up period, which neither influenced subjective symptoms nor caused the recurrence of PEDs.
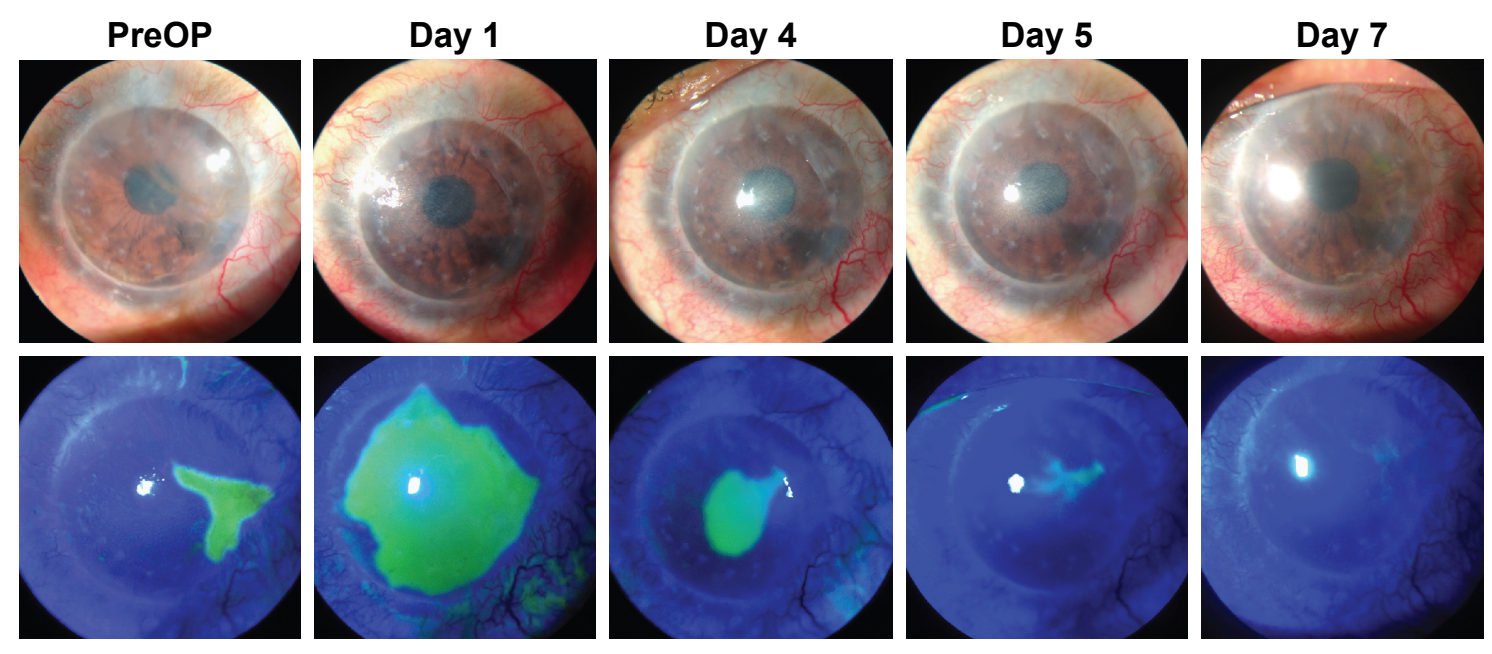

Figure 2 Graft surface prior to and following wet transepithelial phototherapeutic keratectomy for persistent epithelial defects in the graft in patient number 8. Abbreviation: PreOP, preoperative. 


\section{Discussion}

This study demonstrates the potential of wet TE-PTK in the treatment of PEDs in the graft, with the median time for complete reepithelialization of the defect being 6 days. In addition, abatement or complete relief of subjective symptoms was associated with statistically significant improvement in visual acuity, and the effect remained stable throughout the remainder of the follow-up period (the follow-up ranged from 6 to 12 months).

Potential surface epithelial abnormalities following PKP include punctate epithelial keratitis, punctate erosions, vortex keratopathy, filamentary keratitis, and macroepithelial defects. ${ }^{3}$ Early postoperatively, the latter are found in $26 \%-76 \%$ of operated eyes, ${ }^{9,10}$ with postoperative epithelial healing time ranging from 1 day to 12 days (median: 2 days). ${ }^{9}$ PEDs are substantially less common, and their frequency varies with indication for PKP, ranging from $0 \%$ to $5.9 \% .{ }^{11}$

Besides the neurotrophic state common in eyes with PED after keratoplasty, some additional factors associated with the initial host status also seem to contribute to PED in them. Fu et $\mathrm{al}^{12}$ have reported that these factors include infrequent blinking, lagophthalmos, and pathogenic symblepharon. LSCD also significantly contributes to the postoperative risk of PED, since after transplantation, the donor epithelium is replaced by the host epithelium. ${ }^{12}$ Considering all these risk factors, patients with ocular chemical injuries seem to be especially predisposed to the development of PEDs in the graft, which was partially confirmed by this study: more than half of the cases were patients who had sustained a chemical injury. The 2 patients who underwent keratoplasty for corneal endothelial and epithelial dystrophy (EED) fall under the category of those with most common nonchemical-injuryrelated causes of PED. Wagoner et $\mathrm{al}^{11}$ have demonstrated that PEDs in the graft were most commonly associated with prekeratoplasty corneal edema.

All the cases included in our study were those with PEDs that had persisted despite customary treatments (BSCL, AMT, and/or tarsorrhaphy) for $>3$ months. Therefore, the cases included in the study were related to the most common causes of PEDs and responded to TE-PTK after being unresponsive to conventional treatment options. Since insufficient adhesion of the basal epithelial layers to the basement membrane underlies RCEs, approaches to their treatment may involve measures aimed at either decreasing the mechanical effect on the poorly attached epithelium or strengthening epithelial adhesion to the membrane.

PEDs in the graft and RCE may differ in cause (eg, the former, but not the latter, may be caused by epithelial failure of the graft); however, poor epithelial adhesion to the underlying basement membrane may be important in both diseases. The defective adhesion is a potentially major contributor to the persistence of the epithelial defect in generally normal engraftment (in the absence of stromal or endothelial failure), which was taken into consideration in the inclusion/ exclusion criteria for our study. Consequently, conventional RCE treatment options aimed at maintaining and improving epithelial adhesion to the membrane had been used as a firstline treatment for PEDs in the graft in patients of the study. Intensive topical lubrication and BSCL are the simplest RCE treatment options.

Erosion recurrence is common following these approaches, and they failed to provide long-term relief from PEDs in the graft in patients of the current study. AMT is commonly performed to manage RCEs in partial LSCD ${ }^{13}$ it was not, however, effective for PEDs in the graft in our patients with partial LSCD. Moreover, AMT failed to provide long-term relief from PEDs in the graft in patients without LSCD. Mechanical de-epithelization (MDE) ${ }^{14}$ and anterior stromal puncture (ASP) $)^{15,16}$ have been reported as more active measures for treatment of RCEs, but they were not performed in patients of the current study. MDE removes pathologically altered marginal epithelium, whereas ASP enhances the adhesion between the basement membrane of the epithelium and the underlying stroma, and, each of these 2 techniques is technically easier to perform than TE-PTK. The advantage of the latter is, however, that it combines the 2 benefits mentioned earlier.

In the management of recurrent erosions, a PTK is usually reserved for cases in which more affordable approaches (eg, treatment with AMT and/or BSCL) have failed. In addition, a repeat PTK appears to be effective in alleviating symptoms in those patients who fail a primary treatment. ${ }^{7}$ The mechanism of action of PTK is based on the adhesion strengthening of the basal layer of corneal epithelium to the cornea portion resurfaced with a laser. Experimental studies have confirmed an increase in the numbers of anchoring fibrils and hemidesmosomes in basal epithelium following PTK. ${ }^{17}$ In addition, PTK removes superficial stromal layers that have been altered as a result of chronic inflammation and denudation, and that disrupt normal cell-cell adhesion. ${ }^{18}$ We believe that, for our PED cases associated with either post-PKP keratitis or pre-PKP EED (ie, the conditions in which the superficial stroma of the graft may have undergone some special changes), ablation of the superficial stroma was more important than for the remainder of our PED cases. It is for these cases (patients 2, 5, and 6) that total ablation depth 
was the greatest $(58-60 \mu \mathrm{m})$. In the PED cases associated with partial LSCD and low tear production, 1) formation of a uniformly smooth stromal surface in the PED area and 2) adequate moistening in the postoperative period were of primary importance. We suppose that PED cases with extremely low tear production are poor candidates for wet TE-PTK.

Various PTK techniques are available, eg, PTK after mechanical ${ }^{7,19}$ or alcohol-assisted ${ }^{19}$ removal of the affected epithelium, TE-PTK, ${ }^{19,20}$ and TE-PTK with a wet PTK ablation. ${ }^{21}$ The technique we used in this study comes closest to the latter technique, which involves complete ablation of the epithelium, with the areas of thinning of the epithelium flooded with balanced salt solution (in these areas, laser energy is expended for evaporation rather than for epithelial ablation). Our "wet ablation" step (ie, the first stage of ablation) involved a $50 \mu \mathrm{m}$ ablation, aimed at removing a major portion of epithelial tissue without stromal ablation at the site of epithelial defect. Additional ablations within a "wet ablation" step were monitored visually, allowing us to remove the remaining epithelium at this site. The second stage of ablation was performed up to a depth of $10 \mu \mathrm{m}$ and was aimed to flat the corneal surface in the best possible way. Therefore, in the wet TE-PTK, the tear fluid is applied as a masking agent to the zone of PED, whereas the epithelium is used as a natural masking agent outside this zone. This approach allows achieving even removal of the epithelium, with the following even ablation of Bowman's layer and anterior stroma. It is noteworthy that the ablation is performed so as to have the zone of ablation covering and extending somewhat beyond the defect, and thus, the visibility of the boundary between the PED area and the unaffected anterior surface disappears. Another advantage of this approach is that the cornea is not exposed to mechanical stress, which can be important for patients who have undergone PKP. Therefore, if conservative management proves to be ineffective at resolving PEDs in the graft following PKP, it can be followed, at any time, by PTK of the graft. This is also justified by the fact that the outcomes of PTK remained stable even after sutures were removed, with no recurrence of PED.

Our study is limited by the fact that some nonhost factors (eg, state of the donor fragment, ${ }^{9}$ diabetes in the donor, and longer death-to-enucleation time) predisposing to epithelial defects after $\mathrm{PKP}^{22}$ were not considered in the study. In addition, prior to PTK, we did not use autologous serum, and therefore, not all potential means were tried to obtain PED healing. Nevertheless, it was very unlikely that this measure could be effective after failure of AMT or tarsorrhaphy.
The third limitation is the absence of data on the preoperative and postoperative refraction (or keratometry) and on the postoperative hyperopic shift. We did not perform evaluation of the refraction (or keratometry) pre- and postoperatively, although it could elucidate the contribution, if any, of the hyperopic shift to the postoperative refraction of our patients. Presence of the epithelial defect before the procedure made performing refractometry and keratometry difficult, if possible at all. We, however, believe that there could hardly be any clinically significant hyperopic shift in our study as the depth of ablation of the stroma responsible for hyperopic shift did not exceed $10 \mu \mathrm{m}$.

\section{Conclusion}

This study demonstrates the efficacy of wet TE-PTK even in the most severe cases of PED in the graft, which have been unresponsive to other treatments for long periods of time. Wet TE-PTK allows the ophthalmologist to achieve 1) prompt reepithelialization of the defect, 2) relief of the symptoms of PED, and 3) improved visual acuity for long, irrespective of the initial reason for keratoplasty and of the cause of PEDs in the graft.

\section{Acknowledgments}

The authors thank Oleksandr V Oleksiienko for his assistance in translating the article. The authors have had no funding for this study.

\section{Disclosure}

The authors report no conflicts of interest in this work.

\section{References}

1. Ramamurthi S, Rahman MQ, Dutton GN, Ramaesh K. Pathogenesis, clinical features and management of recurrent corneal erosions. Eye (Lond). 2006;20:635-644.

2. Katzman LR, Jeng BH. Management strategies for persistent epithelial defects of the cornea. Saudi J Ophthalmol. 2014;28(3):168-172.

3. Feiz V, Mannis MJ, Kandavel G, et al. Surface keratopathy after penetrating keratoplasty. Trans Am Ophthalmol Soc. 2001;99:159-168. discussion 168-170.

4. Price FW Jr, Whitson WE, Collins KS, Marks RG. Five-year corneal graft survival: a large, single-center patient cohort. Arch Ophthalmol. 1993;111(6):799-805.

5. Mehlan J, Steinberg J, Traber L, Katz T, Linke SJ. Recurrence rate and subjective symptoms after standardized (Hamburg protocol) phototherapeutic keratectomy on recurrent corneal erosions. Graefes Arch Clin Exp Ophthalmol. 2016;254(10):2005-2009.

6. Dedes W, Faes L, Schipper I, Bachmann LM, Thiel MA. Phototherapeutic keratectomy (PTK) for treatment of recurrent corneal erosion: correlation between etiology and prognosis - prospective longitudinal study. Graefes Arch Clin Exp Ophthalmol. 2015;253(10):1745-1749.

7. Maini R, Loughnan MS. Phototherapeutic keratectomy re-treatment for recurrent corneal erosion syndrome. Br J Ophthalmol. 2002;86(3): $270-272$. 
8. Reeves SW, Kang PC, Zlogar DF, Gupta PK, Stinnett S, Afshari NA. Recurrent corneal erosion syndrome: a study of 364 episodes. Ophthalmic Surg Lasers Imaging. 2010;9:1-2.

9. Meyer RF, Bobb KC. Corneal epithelium in penetrating keratoplasty. Am J Ophthalmol. 1980;90(2):142-147.

10. Sugar A, Meyer RF, Bahn CF. A randomized trial of pressure patching for epithelial defects after keratoplasty. Am J Ophthalmol. 1983; 95(5):637-640.

11. Wagoner MD, Ba-Abbad R, Al-Mohaimeed M, Al-Swailem S, Zimmerman MB; King Khaled Eye Specialist Hospital Corneal Transplant Study Group. Postoperative complications after primary adult optical penetrating keratoplasty: prevalence and impact on graft survival. Cornea. 2009;28(4):385-394.

12. Fu Y, Liu J, Tseng SC. Ocular surface deficits contributing to persistent epithelial defect after penetrating keratoplasty. Cornea. 2012;31(7):723-729.

13. Kheirkhah A, Casas V, Raju VK, Tseng SC. Sutureless amniotic membrane transplantation for partial limbal stem cell deficiency. Am J Ophthalmol. 2008;145(5):787-794.

14. Buxton JN, Fox ML. Superficial epithelial keratectomy in the treatment of epithelial basement membrane dystrophy. A preliminary report. Arch Ophthalmol. 1983;101:392-395.

15. Avni Zauberman N, Artornsombudh P, Elbaz U, Goldich Y, Rootman DS, Chan CC. Anterior stromal puncture for the treatment of recurrent corneal erosion syndrome: patient clinical features and outcomes. Am J Ophthalmol. 2014;157(2):273-279.
16. Malecha MA. Anterior stromal puncture for recurrent corneal erosion after laser in situ keratomileusis. J Cataract Refract Surg. 2004;30(2): 496-498.

17. Wu WCS, Stark WJ, Green WR. Corneal wound healing after 193 nm excimer laser keratectomy. Arch Ophthalmol. 1991;109:1426-1432.

18. SunderRaj N, Geiss M, Fantes F, et al. Healing of excimer laser ablated monkey corneas: an immunohistochemical evaluation. Arch Ophthalmol. 1990;108(11):1604-1610.

19. Sati A, Ramappa M, Sharma N, et al. Bilateral granular dystrophy: a clinicopathogenetic correlation after alcohol assisted debridement with phototherapeutic keratectomy. Med J Armed Forces India. 2015; 71(Suppl 1):S1-S4.

20. Reinstein DZ, Archer TJ, Dickeson ZI, Gobbe M. Transepithelial phototherapeutic keratectomy protocol for treating irregular astigmatism based on population epithelial thickness measurements by artemis very high-frequency digital ultrasound. J Refract Surg. 2014;30(6): 380-387.

21. Reinstein DZ, Gobbe M, Archer TJ, Youssefi G, Sutton HF. Stromal surface topography-guided custom ablation as a repair tool for corneal irregular astigmatism. J Refract Surg. 2015;31(1):54-59.

22. Chou L, Cohen EJ, Laibson PR, Rapuano CJ. Factors associated with epithelial defects after penetrating keratoplasty. Ophthalmic Surg. 1994;25(10):700-703.
Clinical Ophthalmology

\section{Publish your work in this journal}

Clinical Ophthalmology is an international, peer-reviewed journal covering all subspecialties within ophthalmology. Key topics include: Optometry; Visual science; Pharmacology and drug therapy in eye diseases; Basic Sciences; Primary and Secondary eye care; Patient Safety and Quality of Care Improvements. This journal is indexed on

Submit your manuscript here: http://www.dovepress.com/clinical-ophthalmology-journal

\section{Dovepress}

PubMed Central and CAS, and is the official journal of The Society of Clinical Ophthalmology (SCO). The manuscript management system is completely online and includes a very quick and fair peer-review system, which is all easy to use. Visit http://www.dovepress.com/ testimonials.php to read real quotes from published authors. 